\title{
Changes in Attitude to Waterpipe Tobacco Smoking among Youngsters in Eastern Province, Saudi Arabia: A Cross-Sectional Study
}

\author{
Royes Joseph*, Dhfer Alshayban
}

\begin{abstract}
Background: A growing number of epidemiological evidence suggests a significant increase in waterpipe tobacco smoking, and its potential to become a major public health concern in most Arabic countries, including Saudi Arabia. Methods: A cross-sectional study was carried out to assess the prevalence of intention to quit among ever users of waterpipe and intention to start among the never users. The study also investigated the barriers that may prevent users from quitting or trigger the nonusers to start waterpipe smoking. The study consisted of 464 university students from Eastern Province, Saudi Arabia. Results: One hundred and sixty-eight (36.2\%) participants were responded that they had WTS at least one time in the past. Among the ever users of WTS, 120 (71.4\%) participants had made an attempt or more to quit WTS in the past, $64(38.1 \%)$ had made more than one attempt, and nearly two-third expressed the intention to quit WTS in the future. Forty (13.5\%) out of 296 never-users expressed their intention to start WTS in the future. The study further showed that peer influence, social acceptance, and risk perception were significant predictors of intention to start or stop WTS among students. Conclusion: It is promising that substantial users have the intention to discontinue WTS, though a fraction of never users wish to try WTS in the future.
\end{abstract}

Keywords: Smoking water pipes- intention-to-quit- intention-to-start- youngsters- Saudi Arabia

Asian Pac J Cancer Prev, 22 (5), 1443-1450

\section{Introduction}

The water pipe device indirectly heats tobacco and produces smoke, which then passes through a column of water before being inhaled through the mouth using a pipe. It has different names, such as waterpipe, hookah, narghile, and arghile. A growing number of epidemiological evidence suggests a significant increase in waterpipe tobacco smoking (WTS), and its potential to become a major public health concern in most Arabic countries, including Saudi Arabia (Maziak et al., 2004a; Maziak et al., 2004b; Maziak, 2004). The increased use of WTS among the Saudi population may be attributed to different reasons, including cultural reasons and the misconception that smoking waterpipe is safe and not as harmful as smoking cigarettes. According to the World Health Organization (WHO) and other studies, WTS may be addictive as in other forms of tobacco use and may cause similar health risks that smoking cigarettes can cause, including lung cancer, respiratory illness, and low birth weight (Martinasek et al., 2011; Akl et al., 2011; WHO Study Group on Tobacco Product Regulation, 2015; Soule et al., 2015; Jawad et al., 2018; Qasim et al., 2019).

As part of tobacco-free initiatives, WHO has introduced MPOWER measures to promote government action on tobacco control (WHO EMRO, 2010). MPOWER consists of six evidence-informed and cost-effective interventions: Monitoring tobacco use, Protecting people from tobacco use through smoke-free policies, Offering cessation programs, health Warnings, Enforcing a ban on promotion, and make tobacco products less affordable by Raising taxes on them. In line with these measures, Saudi Arabia has enforced laws preventing smoking in most public places (Heydari et al., 2018; WHO, 2019). The country further ensured the availability of smoking cessation support through primary care health centers, availability of nicotine replacement therapy, Bupropion, and Varenicline through pharmacies with full health insurance coverage, and offered a toll-free telephone help-line to discuss cessation (Heydari et al., 2018; WHO, 2019). In the country, health warnings on tobacco packages are mandated by law, and a number of anti-tobacco mass media campaigns were aired (Heydari et al., 2018; WHO, 2019). As per the WHO report on global tobacco pandemic, Saudi Arabia has recently implemented the MPOWER measures at the moderate to best practice level except on the monitoring aspect (WHO, 2019). A significant reduction in the prevalence of tobacco use 
would be expected if the implementation of these measures at the highest level (WHO EMRO, 2010). The overall reduction is expected through the increase in smoking quit rate and reduction in smoking initiation rate.

The smoking-related beliefs and the intention to quit or start smoking among Saudi youth have been the focus of smoking cessation research. The smoking-related beliefs could be explained by a health belief model that is used to predict an action that people might take based on the belief to prevent, to screen for, or to control disease situations (Taylor et al., 2006; Balbach et al., 2006; Glanz et al., 2015). The first component of this model is the perception of susceptibility which refers to beliefs of users regarding the likelihood of having some negative consequences of this habit (Taylor et al., 2006; Balbach et al., 2006; Glanz et al., 2015). The second component is the perception of the seriousness of the health outcomes and the possible social of smoking that might impact the decision of people toward quitting or starting smoking (Balbach et al., 2006; Glanz et al., 2015). The third component of the model is the perception of the benefits of quitting or starting smoking. Furthermore, the perceptions of barriers and obstacles such as social barriers (i.e., having a close friend who smokes waterpipe) could lead the person to decide either to start or to quit waterpipe smoking (Balbach et al., 2006; Glanz et al., 2015).

There is a lack of studies to investigate the factors related to intention to quit or start waterpipe smoking among smokers in Saudi Arabia. The present study has two objectives: 1) to determine the prevalence of intention to quit among the WTS users and the intention to start among the nonusers; 2) to examine socio-demographic characteristics, smoking-related beliefs as predictors of intention to quit and intention to start WTS among Saudi university students. The impact of our study was that it might help to know in-depth the social, cultural, and other factors around smoking waterpipe, in order to overcome all the barriers that may prevent users from quitting or trigger nonusers to start WTS.

\section{Materials and Methods}

\section{Study design and sample}

We conducted a questionnaire-based cross-sectional study among university students. The study sample was selected from various colleges of a leading public university in the Eastern province of Saudi Arabia. The university has more than 45,000 registered students over 21 colleges that spread over the Eastern Province, Saudi Arabia. The study sample comprised of male and female undergraduate students aged below 18 years under health, engineering, and arts and science stream of studies. A minimum sample size of 323 participants was required to estimate a prevalence of $30 \%$ with $5 \%$ absolute precision and a $95 \%$ confidence level. Therefore we targetted a sample of 500 students with the expectation of incomplete data from some students. A group of final-year students had been selected and trained for data collection using a questionnaire. The data collectors approached students at public places, such as the atrium, cafeteria, library, and other open areas, within the university in order to collect the data. The purpose of the study was explained, and consent for participation was obtained from the participating students. The participants were requested to fill the questionnaire with minimal support from the data collectors. Ethical approval was obtained from the Institutional Ethics Committee, College of Clinical Pharmacy, Imam Abdulrahman Bin Faisal University.

\section{Questionnaire}

The questionnaire has four sections: socio-demographic information of participants, smoking status and family history, the perceptions on WTS, and the information on the willingness to quit or try WTS in the future. The first three sections were adapted from literature on WTS use (Primack et al., 2008).

\section{Socio-demographic details}

Data on age, gender, study stream, marital status, area of residence (urban/rural), and monthly family income of participants were collected.

\section{Smoking status and family history}

Participants were asked if they had smoked cigarettes, e-cigarettes, and waterpipe in the past ever in addition to a question on their 30-days use. The frequency of WTS use among friends and family members were also obtained.

\section{Perceptions on WTS}

The questionnaire contained eight items to assess risk-perception about WTS, knowledge on the hazards of WTS, and the normative belief on the social acceptance of WTS. The beliefs about the addictive and harmful effects of WTS compared to cigarettes were rated on a five-point scale. The lowest score of ' 0 ' indicated 'WTS is much less addictive/harmful than cigarettes', and the highest score of 4 indicated 'WTS is much more addictive/harmful than cigarettes'. The overall risk-perception was assessed using the sum of the two items with a lower total score indicates the higher the false perception. The knowledge on the hazards of WTS was assessed by asking the participants to rate five statements about WTS. The statements were 1) water filters the toxic elements of WTS, 2) WTS is free of tar, 3) WTS is free of nicotine, 4) WTS is free of carbon monoxide, and 5) no increased risk of cardiovascular diseases (CVD) due to WTS. The participants rated the statements on a five-point Likert scale ranging 'strongly agree (score 0)' to 'strongly disagree (score 4)'. A total score of these five items were calculated as a measure of knowledge on hazards of WTS with a lower score indicates lower the knowledge. In order to assess the normative belief on social acceptance of WTS, participants were requested to rate their belief on acceptance of WTS in the society on a four-point scale ranging 'not acceptable' to 'very acceptable'.

\section{Intention to quit or start in the future}

Participants who had used WTS in the past were asked about their previous attempt to quit, previous use of cessation mediations/programs, and their willingness to quit in the future. Their self-confidence with the quit decision was also rated. Participants who never used WTS 
in the past were also asked their intention to try WTS in the future.

\section{Data analysis}

'Ever user' of WTS was a participant who used WTS in the past, while 'never user' of WTS was a participant who never used WTS in the past. We estimated the prevalence of intention to quit among the ever users and intention to try among never users. For the purpose of analysis, the total risk perception score and knowledge score were categorized into three levels using tertiles: categories with high scores (low favored for WTS), moderate scores, and low scores (highly favored for WTS). Further, categories of individual items were collapsed into three categories.

Data were summarized using frequencies and percentages. A Chi-square test for association was used to identify the predictors of intention to quit and start WTS in the future. A p-value of less than 0.05 was considered statistically significant. Analyses were carried out using SPSS Statistics version 24.0.

\section{Results}

The study sample consisted of 464 participants, of which $268(57.8 \%)$ were males. The description of the participants was detailed in Table 1.

Ever users of WTS

One hundred and sixty-eight (36.2\%) participants were responded that they had WTS at least one time in the past (Figure 1). Column 5 in Table 2 reports the prevalence of ever use of WTS by participants' characteristics. Significantly higher WTS prevalence of 43.3\% (116/268), 41.3\% (124/300), 72.5\% (74/102), and $52.5 \%(106 / 202)$ were reported among male gender, students of health cluster, current users of cigarettes and e-cigarettes, and students who had family history of occasional/frequent use of WTS, respectively, compared to their corresponding counterparts $(\mathrm{p}<0.05)$. Further,
Attitude to Waterpipe Tobacco Smoking among Youngsters as shown in Table 3 (column 5), significantly lower WTS prevalence of $28.6 \%$ (40/140), 25.0\% (38/152), $22.2 \%$ (28/126), 23.4\% (36/154), 24.4\% (44/180), 26.0\% (54/208), 26.9\% (70/260), and 17.8\% (26/146) among students who believed 'waterpipe is more harmful than cigarettes', 'waterpipe is more addictive than cigarettes', 'water does not filter toxins', 'STS contains tar', 'STS contains carbon monoxide', 'increased risk of CVD', and 'STS is not socially acceptable', respectively, compared to their corresponding counterparts $(\mathrm{p}<0.05)$.

Intention to start WTS in the future among never-users

There were $40(13.5 \%)$ out of 296 never-users were

Table 1. Socio-Demographics Characteristics of Participants $(\mathrm{N}=464)$

\begin{tabular}{lc}
\hline Factors & Total n (\%) \\
\hline Gender & $268(57.8 \%)$ \\
Male & $196(42.2 \%)$ \\
Female & \\
Area of study & $300(64.7 \%)$ \\
$\quad$ Health & $78(16.8 \%)$ \\
Engineering & $86(18.5 \%)$ \\
Arts, Science and Management & \\
Locality & $378(81.5 \%)$ \\
Urban & $86(18.5 \%)$ \\
Rural & \\
Marital status & $436(94 \%)$ \\
Single & $28(6 \%)$ \\
Married & \\
Family monthly income & $74(15.9 \%)$ \\
Less than 5,000 SR & $142(30.6 \%)$ \\
$5,000-15,000$ & $154(33.2 \%)$ \\
16,000-25,000 & $94(20.3 \%)$ \\
Greater than 25,000 &
\end{tabular}

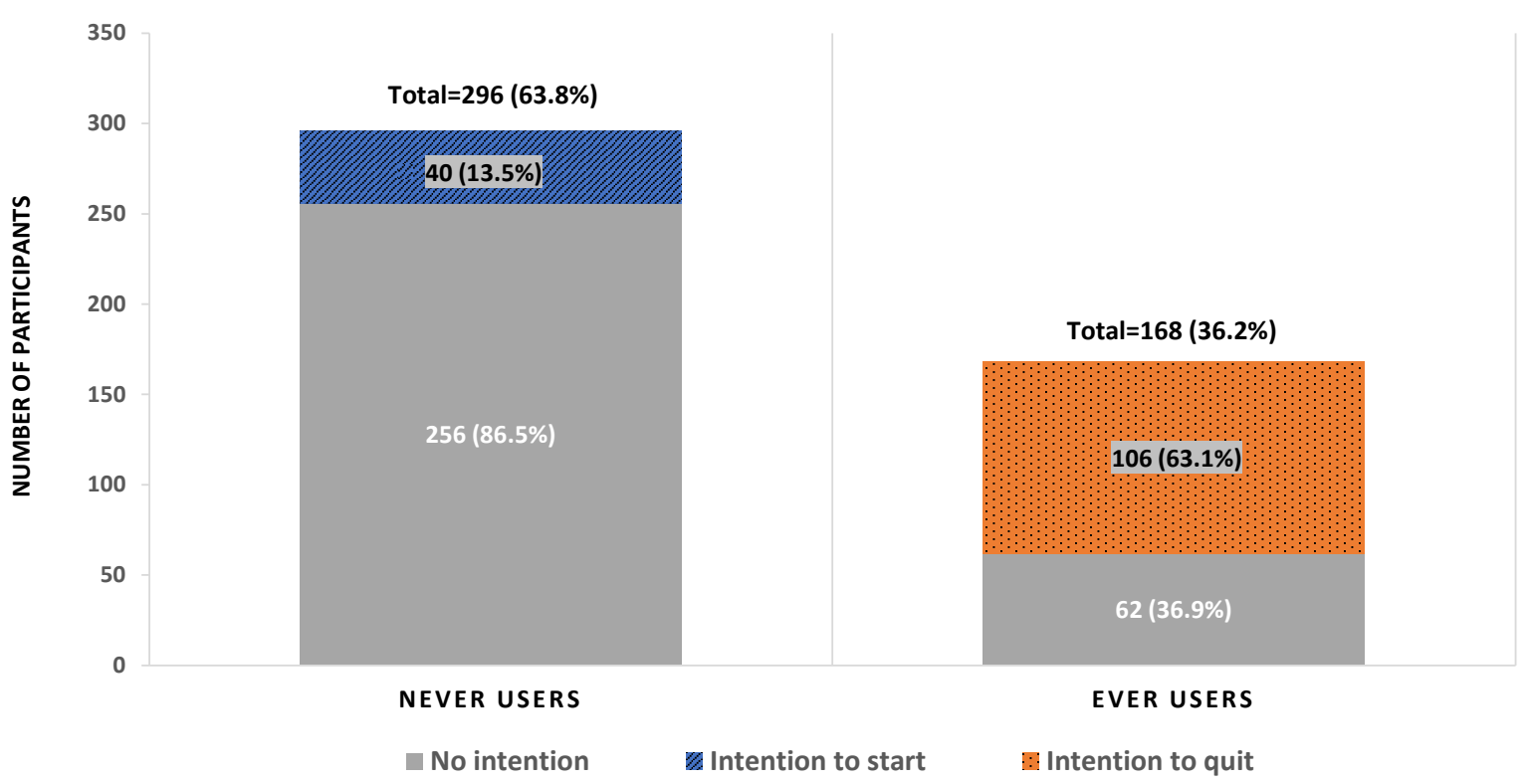

Figure 1. Proportion of Participants Showed Intention to Start and Intention to Quit Waterpipe Smoking 
Table 2. Socio-Demographics and Cigarettes Smoking among Ever and Never Users of Waterpipe Tobacco Smoking

\begin{tabular}{|c|c|c|c|c|c|c|c|}
\hline \multirow[t]{3}{*}{ Variables } & & \multicolumn{3}{|c|}{ Never users $(\mathrm{N}=296)$} & \multicolumn{3}{|c|}{ Ever users $(\mathrm{N}=168)$} \\
\hline & & \multirow{2}{*}{$\begin{array}{l}\text { Total } \\
\mathrm{n}(\%)\end{array}$} & \multicolumn{2}{|c|}{ Intention to start $(\mathrm{N}=40)$} & \multirow{2}{*}{$\begin{array}{l}\text { Total } \\
\mathrm{n}(\%)\end{array}$} & \multicolumn{2}{|c|}{ Intention to quit $(\mathrm{N}=106)$} \\
\hline & & & $\mathrm{n}(\%)$ & p-value & & $\mathrm{n}(\%)$ & p-value \\
\hline \multicolumn{8}{|l|}{ Gender } \\
\hline & Male & $152(56.7)$ & $28(18.4)$ & $0.011 *$ & $116(43.3)^{*}$ & $86(74.1)$ & $<0.001^{*}$ \\
\hline & Female & $144(73.5)$ & $12(8.3)$ & & $52(26.5)$ & $20(38.5)$ & \\
\hline \multicolumn{8}{|c|}{ Area of study } \\
\hline & Health & $176(58.7)$ & $18(10.2)$ & $<0.001 *$ & $124(41.3)^{*}$ & $72(58.1)$ & 0.072 \\
\hline & Engineering & $58(74.4)$ & $4(6.9)$ & & $20(25.6)$ & $16(80.0)$ & \\
\hline & Arts \& Science & $62(72.1)$ & $18(29.0)$ & & $24(27.9)$ & $18(75.0)$ & \\
\hline \multicolumn{8}{|l|}{ Locality } \\
\hline & Urban & $236(62.4)$ & $32(13.6)$ & 0.964 & $142(37.6)$ & $96(67.6)$ & $0.005^{*}$ \\
\hline & Rural & $60(69.8)$ & $8(13.3)$ & & $26(30.2)$ & $10(38.5)$ & \\
\hline \multicolumn{8}{|c|}{ Marital status } \\
\hline & Single & $282(64.7)$ & $38(13.5)$ & 0.931 & $154(35.3)$ & $100(64.9)$ & 0.101 \\
\hline & Married & $14(50)$ & $2(14.3)$ & & $14(50.0)$ & $6(42.9)$ & \\
\hline \multicolumn{8}{|c|}{ Family monthly income } \\
\hline & Less than $5000 \mathrm{SR}$ & $44(59.5)$ & $4(9.1)$ & 0.375 & $30(40.5)$ & $22(73.3)$ & 0.196 \\
\hline & $5,000-15,000$ & $100(70.4)$ & $18(18)$ & & $42(29.6)$ & $30(71.4)$ & \\
\hline & $16,000-25,000$ & $92(59.7)$ & $12(13)$ & & $62(40.3)$ & $34(54.8)$ & \\
\hline & Greater than 25,000 & $60(63.8)$ & $6(10)$ & & $34(36.2)$ & $20(58.8)$ & \\
\hline \multicolumn{8}{|c|}{ Cigarettes used within 30 days } \\
\hline & No & $268(74.0)$ & $24(9.0)$ & $<0.001 *$ & $94(26.0)^{*}$ & $62(66.0)$ & 0.386 \\
\hline & Yes & $28(27.5)$ & $16(57.1)$ & & $74(72.5)$ & $44(59.5)$ & \\
\hline \multicolumn{8}{|c|}{ E-Cigarettes used with in 30 days } \\
\hline & No & $278(70.9)$ & $30(10.8)$ & $<0.001 *$ & $114(29.1)^{*}$ & $78(68.4)$ & $0.038^{*}$ \\
\hline & Yes & $18(25.0)$ & $10(55.6)$ & & $54(75.0)$ & $28(51.9)$ & \\
\hline \multicolumn{8}{|c|}{ Use of Waterpipe by family } \\
\hline & Never used & $134(79.8)$ & $16(11.9)$ & $0.018^{*}$ & $34(20.2)^{*}$ & $32(94.1)$ & $<0.001^{*}$ \\
\hline & Rarely used & $66(70.2)$ & $6(9.1)$ & & $28(29.8)$ & $12(42.9)$ & \\
\hline & Occasionally used & $44(48.9)$ & $4(9.1)$ & & $46(51.1)$ & $26(56.5)$ & \\
\hline & Frequently used & $52(46.4)$ & $14(26.9)$ & & $60(53.6)$ & $36(60.0)$ & \\
\hline
\end{tabular}

*p-value $<0.05$

expressed their intention to start WTS in the future (Figure 1). The proportion of participants who intend to start WTS in the future among never-users was given in Tables 2 and 3 (columns 3 and 4). The proportion among males (18.4\%), students of Arts and Science cluster $(29.0 \%)$, current users of cigarettes $(57.1 \%)$ and e-cigarettes $(55.6 \%)$, students with family history of frequent use of WTS (26.9\%) were significantly higher than the proportions in their corresponding counterparts $(\mathrm{p}<0.05)$. The proportion was lower, but not statistically significant, among students with high-risk perception (6.8\%) and high knowledge score $(10.2 \%)$ compared to students with low-risk perception $(17.9 \%)$ and low knowledge score (18.2\%), respectively. Importantly, $23.1 \%(6 / 26)$ of students who think WTS is well accepted had expressed their intention to use WTS in the future; while it was only $6.7 \%(8 / 120)$ among students who think WTS is not accepted socially.
Previous quitting attempt and intention to quit WTS in the future among ever users

Among the ever users of WTS, 120 (71.4\%) participants had made an attempt or more to quit WTS in the past; 64 (38.1\%) had made more than one attempt. More than half of users (94/168) were aware of cessation services for WTS. However, only $14.3 \%$ (24/168) had used the service: Bupropion was used by four participants, Varenicline or NicoDerm CQ was used by 16 participants, and other medications were used by another four participants.

Among the ever users of WTS, nearly two-thirds (106/168) expressed the intention to quit WTS in the future (Figure 1). The proportion by participants' characteristics was given in Tables 2 and 3 (columns 6 and 7). The proportion was significantly higher among males $(74.1 \%)$, urban students $(67.6 \%)$, e-cigarettes non-smokers $(68.4 \%)$, and students who did not have the family history of WTS use $(94.1 \%)$, compared to their 
DOI:10.31557/APJCP.2021.22.5.1443

Attitude to Waterpipe Tobacco Smoking among Youngsters

Table 3. Risk-Perception, Knowledge and Normative Beliefs among Ever and Never Users of Waterpipe Tobacco Smoking

\begin{tabular}{|c|c|c|c|c|c|c|}
\hline \multirow[t]{3}{*}{ Variables } & \multicolumn{3}{|c|}{ Never users $(\mathrm{N}=296)$} & \multicolumn{3}{|c|}{ Ever users $(\mathrm{N}=168)$} \\
\hline & \multirow{2}{*}{$\begin{array}{l}\text { Total } \\
\text { n (\%) }\end{array}$} & \multicolumn{2}{|c|}{$\begin{array}{l}\text { Intention to start } \\
\qquad(\mathrm{N}=40)\end{array}$} & \multirow{2}{*}{$\begin{array}{l}\text { Total } \\
\text { n (\%) }\end{array}$} & \multicolumn{2}{|c|}{$\begin{array}{l}\text { Intention to quit } \\
\quad(\mathrm{N}=106)\end{array}$} \\
\hline & & $\mathrm{n}(\%)$ & p-value & & $\mathrm{n}(\%)$ & p-value \\
\hline \multicolumn{7}{|l|}{ Belief about harmfulness } \\
\hline Waterpipe is more harmful & $100(71.4)$ & $8(8.0)$ & 0.139 & $40(28.6)^{*}$ & $34(85.0)$ & $<0.001^{*}$ \\
\hline Waterpipe is equally harmful & $100(68.5)$ & $16(16.0)$ & & $46(31.5)$ & $34(73.9)$ & \\
\hline Waterpipe is less harmful & $96(53.9)$ & $16(16.7)$ & & $82(46.1)$ & $38(46.3)$ & \\
\hline \multicolumn{7}{|l|}{ Belief about addictiveness } \\
\hline Waterpipe is more Addictive & $114(75.0)$ & $12(10.5)$ & 0.161 & $38(25.0)^{*}$ & $26(68.4)$ & $0.024 *$ \\
\hline Waterpipe is equally Addictive & $74(68.5)$ & $8(10.8)$ & & $34(31.5)$ & $26(76.5)$ & \\
\hline Waterpipe is less Addictive & $108(52.9)$ & $20(18.5)$ & & $96(47.1)$ & $54(56.3)$ & \\
\hline \multicolumn{7}{|l|}{ Risk-perception score (overall) } \\
\hline Low (highly favoured for waterpipe) & $56(48.3)$ & $10(17.9)$ & 0.084 & $60(51.7)^{*}$ & $26(43.3)$ & $<0.001^{*}$ \\
\hline Moderate & $152(63.9)$ & $24(15.8)$ & & $86(36.1)$ & $64(74.4)$ & \\
\hline High (Less favoured for waterpipe) & $88(80.0)$ & $6(6.8)$ & & $22(20.0)$ & $16(72.7)$ & \\
\hline \multicolumn{7}{|l|}{ Belief about water filtering of toxins } \\
\hline Completely/Substantially & $68(56.7)$ & $10(14.7)$ & 0.151 & $52(43.3)^{*}$ & $24(46.2)$ & $0.007 *$ \\
\hline Moderately & $130(59.6)$ & $22(16.9)$ & & $88(40.4)$ & $64(72.7)$ & \\
\hline Slightly/Nothing & $98(77.8)$ & $8(8.2)$ & & $28(22.2)$ & $18(64.3)$ & \\
\hline \multicolumn{7}{|l|}{ Belief about absence of tar } \\
\hline Agree & $138(57.5)$ & $26(18.8)$ & $0.031 *$ & $102(42.5)^{*}$ & $58(56.9)$ & 0.074 \\
\hline Neutral & $40(57.1)$ & $2(5.0)$ & & $30(42.9)$ & $20(66.7)$ & \\
\hline Disagree & $118(76.6)$ & $12(10.2)$ & & $36(23.4)$ & $28(77.8)$ & \\
\hline \multicolumn{7}{|l|}{ Belief about absence of nicotine } \\
\hline Agree & $118(57.8)$ & $20(16.9)$ & 0.298 & $86(42.2)^{*}$ & $56(65.1)$ & 0.297 \\
\hline Neutral & $42(52.5)$ & $6(14.3)$ & & $38(47.5)$ & $20(52.6)$ & \\
\hline Disagree & $136(75.6)$ & $14(10.3)$ & & $44(24.4)$ & $30(68.2)$ & \\
\hline \multicolumn{7}{|l|}{ Belief about absence of $\mathrm{CO}$} \\
\hline Agree & $114(54.3)$ & $18(15.8)$ & 0.619 & $96(45.7)^{*}$ & $62(64.6)$ & 0.317 \\
\hline Neutral & $28(60.9)$ & $4(14.3)$ & & $18(39.1)$ & $11(61.1)$ & \\
\hline Disagree & $154(74.0)$ & $18(11.7)$ & & $54(26.0)$ & $38(70.4)$ & \\
\hline \multicolumn{7}{|l|}{ Belief about increased risk of CVD } \\
\hline Agree & $190(73.1)$ & $24(12.6)$ & 0.764 & $70(26.9)^{*}$ & $54(77.1)$ & $0.005^{*}$ \\
\hline Neutral & $48(66.7)$ & $8(16.7)$ & & $24(33.3)$ & $14(58.3)$ & \\
\hline Disagree & $58(43.9)$ & $8(13.8)$ & & $74(56.1)$ & $38(51.4)$ & \\
\hline \multicolumn{7}{|l|}{ Knowledge score (overall) } \\
\hline Low (highly favoured for waterpipe) & $66(47.1)$ & $12(18.2)$ & 0.299 & $74(52.9)^{*}$ & $40(54.1)$ & 0.093 \\
\hline Moderate & $112(65.9)$ & $16(14.3)$ & & $58(34.1)$ & $40(69.0)$ & \\
\hline High (Less favoured for waterpipe) & $118(76.6)$ & $12(10.2)$ & & $36(23.4)$ & $26(72.2)$ & \\
\hline \multicolumn{7}{|l|}{ Normative belief (Social acceptance) } \\
\hline Not acceptable & $120(82.2)$ & $8(6.7)$ & $0.021^{*}$ & $26(17.8)^{*}$ & $24(92.3)$ & $<0.001^{*}$ \\
\hline Somewhat acceptable & $104(68.4)$ & $20(19.2)$ & & $48(31.6)$ & $34(70.8)$ & \\
\hline Moderately acceptable & $46(46.0)$ & $6(13.0)$ & & $54(54.0)$ & $36(66.7)$ & \\
\hline Very acceptable & $26(39.4)$ & $6(23.1)$ & & $40(60.6)$ & $12(30.0)$ & \\
\hline
\end{tabular}

*p-value $<0.05$

corresponding counterparts. Further, the proportion was lower among the students who believe waterpipe is less harmful $(46.3 \%)$, waterpipe is less addictive (56.3\%), water filter toxins substantially (46.2\%), and waterpipe is not associated with CVD (51.4\%). Importantly, less than one-half of participants with a low risk-perception score 
(43.3\%) and participants who believed that shish is very socially acceptable $(30.0 \%)$ were expressed intention to quit WTS in the future.

\section{Discussion}

The present study investigated the prevalence of the previous attempt to quit, and intention quit WTS among waterpipe ever users and the prevalence of intention to start WTS among the never users in the Eastern Province, Saudi Arabia. Further to aid in developing effective strategies for discouraging the use of WTS among youngsters, the study further investigated the differences in their characteristics, including socio-demographics, knowledge, and perception about WTS, between users with and without intention to quit WTS and nonusers with and without intention to start WTS. The study population was undergraduate students. The study shows that more than one-third (36\%) of participants were used WTS at least once in the past with a higher proportion among males than in females. A previous publication was reported that the past 30-day prevalence was $23 \%$ with a narrow gender gap (Alshayban and Joseph, 2019). The previous attempt or the intention to quit may explain the gender difference in proportion. Availability, affordability, and attractiveness of waterpipe may be the key reasons for the higher prevalence of WTS use among youngsters (Maziak et al., 2004c). We found that $63 \%$ of ever users expressed the intention to quit, and $14 \%$ of never users expressed their intention to start in the future. A study from Qatar reported that more than half of waterpipe users admitted to intending to quit the use (Jaam et al., 2016). A similar proportion of intention to quit smoking was reported among cigarette smokers in Saudi Arabia (Al-Zalabani et al., 2015; Almogbel et al., 2016). Although it is promising that substantial users have the intention to discontinue WTS, still a number of never-users expressed their intention to try WTS in the future. Thus, it is quite important to introduce a more pervasive restriction on WTS in public places and make it less attractive in order to help the students to refrain from WTS. Health warning labels are found to be effective in encouraging students to quit WTS (Darawad et al., 2019).

Previous studies have expressed concern over awareness about WTS cessation techniques among the general public and particularly, among the practicing physicians (Jradi, 2017; Romani et al., 2020). The present study reported that nearly three-fourth of ever users had made an attempt or more to quit WTS in the past. Further, only $14 \%$ used a cessation service for WTS, though half of WTS users were aware of such cessation services. More importantly, a systematic review highlighted the lack of evidence on the effectiveness of interventions targeting prevention and cessation of WTS and a need for higher quality effective clinical and behavioral interventions (Jawad et al., 2016).

The study found that more males expressed the intention to quit WTS among the users, and in contradictory, more males also expressed the intention start to start WTS in the future among never users. Thus, the imbalance in the proportions leads to a narrow gender gap on the prevalence of past one-month use of WTS, as reported in our previous study. Our finding was in line with a previous study that assessed the willingness to quit cigarette smoking among youngsters, and the study observed that a substantially higher proportion of males preferred to quit smoking than females (Al-Zalabani et al., 2015). The higher proportions among the male students may be linked to their confidence to stop WTS at any time point.

We observed, as reported in Table 1, that nearly three-fourth of current users of cigarette or e-cigarette were ever users of WTS in comparison with a quarter among the nonusers of cigarette or e-cigarette. In line with this finding, the study further observed that the willingness to quit and intention start WTS is directly associated with the use of other forms of tobacco. In this study, a lower proportion of intent quit and higher intent to start were reported among the cigarette or e-cigarette users. It strongly indicates the popularity and acceptance of WTS among the users of other-form of tobacco (Alshayban and Joseph, 2019).

Smoking behavior of family members and peers is strongly associated with the initiation of WTS among youngsters and women (Baheiraei et al., 2015). A similar association was observed in our study. The study found that WTS use was higher among students with a family history of frequent use of WTS. Importantly, the intent to start rate and the intent to quit rate was higher among the students had the family history of use and did not have the family history, respectively. The smoking behavior among the closed ones may contribute to the level of perceived social acceptance of WTS. Among the never users, only $7 \%$ of students who think WTS is not socially acceptable were showed intention to start WTS while it was 23\% among the students who think WTS is well accepted. Among the ever users, $92 \%$ of students who think WTS is not socially acceptable were showed intention to quit WTS while it was only $30 \%$ among the students who think WTS is well accepted. This indicates the perception of social acceptance of WTS has a significant effect on preventing the participants for refraining from WTS. Therefore, appropriate measures need to be taken for discouraging the use of waterpipe during social gatherings in order to prevent from perceiving WTS as a kind of entertainment and is considered acceptable in society.

Previous studies have demonstrated that the higher prevalence of WTS use is associated with a high level of perceived lack of harmful and addictive effects of WTS among university students (Abu-Rmeileh et al., 2018). In the current study, more than one-third of participants were misconceived that waterpipe is less harmful and less addictive than cigarettes, and a higher proportion of them were WTS users. We observed that the willingness to quit among the users is significantly associated with the misconception. In overall, three-quarters of users with low-risk perception were expressed willingness to quit while only $43 \%$ intended to quit among the students with high-risk perception. Among the nonusers of WTS, a similar difference in the proportion of students who plan to initiate WTS between the levels of risk perception, though it was not statistically significant. The findings indicate that targeting beliefs on the harmfulness and addictiveness may influence the willingness to quit among users and 
desire to try among nonusers. Mandated waterpipe tobacco package warning may result an increase of awareness of the health effects of WTS (King et al., 2019), and thus increase in the level of risk perception (Salloum et al., 2017).

It was found that students who think WTS is free of tar, nicotine, or carbon monoxide are at higher risk of start using WTS compared to those who think otherwise. Alternatively, the students who think the WTS is free of the hazardous contents are less likely to stop WTS among users compared to those who think otherwise. The users who think that WTS has increased risk of CVD are more prone to quit compared to the users who think otherwise. In overall, though not statistically significant, the desire to try WTS was reported by $18 \%$ of the students with knowledge score that highly favored for WTS in comparison with $10 \%$ among the students with knowledge score that less favored for WTS. Similarly, $72 \%$ of students with knowledge scores that less favored for WTS were showed intention to quit WTS in comparison with 54\% among the students with knowledge scores that highly favored for WTS. Thus, it is important to educate and increase the awareness of students and public on the impact of WTS on health. The textual and pictorial warning on waterpipe tobacco boxes is found to be effective in increasing motivation and intention to stop WTS (Hallit et al., 2019).

This is the first study in the Kingdom of Saudi Arabia to investigate the willingness to quit among WTS users and desire to try WTS among nonusers and its association with the risk perception and knowledge on the health effects of WTS. This was a cross-sectional study, and thus causal association could not be established. Prospective studies are required to show how risk perception and knowledge on the health effects of WTS influence the cessation among WTS users and desire to try WTS among nonusers. Though the study sample selection from different colleges ensured participation from the diverse socio-economic background, the majority of participants were from the Eastern Province, Saudi Arabia.

In conclusion, the study identified the impact of peer influence, social acceptance, and risk perception on behavioral intention to start or stop WTS among students. It is promising that substantial users have the intention to discontinue WTS, though a fraction of never users wish to try WTS in the future. Further actions such as introducing more pervasive restrictions on WTS in public places, make it less attractive, mandating health warning on waterpipe tobacco packages, and awareness campaign on the effectiveness of interventions targeting prevention and cessation of WTS is warranted in order to help the students to refrain from WTS.

\section{Author Contribution Statement}

DA conceived the idea, and later developed as a study in consultation with RJ. DA and RJ equally contributed to the study design. DA was responsible for the data collection. RJ was responsible for the data management and statistical analyses. DA drafted the manuscript. Both authors contributed to further revisions to the draft. All authors have read and approved the final manuscript.

\section{Acknowledgements}

The study was approved by the Institutional Ethical Committee at College of Clinical Pharmacy, Imam Abdulrahman Bin Faisal University. Informed consent was obtained from each participant before they participate in the study.

\section{Conflict of Interest}

The authors have no competing interests.

\section{References}

Abu-Rmeileh NME, Alkhuffash O, Kheirallah K, et al (2018). Harm perceptions of waterpipe tobacco smoking among university students in five Eastern Mediterranean Region countries: A cross-sectional study. Tob Induc Dis, 16, 20.

Akl EA, Gunukula SK, Aleem S, et al (2011). The prevalence of waterpipe tobacco smoking among the general and specific populations: a systematic review. BMC Public Health, 11, 244.

Al-Zalabani AH, Abdallah AR, Alqabshawi RI (2015). Intention to quit smoking among intermediate and secondary school students in Saudi Arabia. Asian Pac J Cancer Prev, 16, 6741-7.

Almogbel YS, Abughosh SM, Almeman AA, Sansgiry SS (2016). Factors associated with the willingness to quit smoking among a cohort of university students in the KSA. J Taibah Univ Med Sci, 11, 128-33.

Alshayban D, Joseph R (2019). A call for effective interventions to Curb Shisha tobacco smoking among university students in Eastern Province, Saudi Arabia: Findings from a CrossSectional Study. Asian Pac J Cancer Prev, 20, 2971-7.

Baheiraei A, Shahbazi Sighaldeh S, Ebadi A, et al (2015). The role of family on Hookah smoking initiation in women: A Qualitative Study. Glob J Health Sci, 7, 1-10.

Balbach ED, Smith EA, Malone RE (2006). How the health belief model helps the tobacco industry: individuals, choice, and andquot;informationandquot. Tob Control, 15, iv37-iv43.

Darawad MW, Salloum R, Alhussami M, Maharmeh M (2019). Evaluating health warning messages specific to waterpipe smoking among university students in Jordan. $J$ Am Assoc Nurse Pract, 31, 133-8.

Glanz K, Rimer BK, Viswanath KV (eds) (2015). Health behavior: Theory, research, and practice, 5th ed. Jossey-Bass, San Francisco, CA, US.

Hallit S, Layoun N, Malaeb D, et al. (2019). The impact of textual and pictorial warnings on tumbac (waterpipe tobacco) boxes on the motivation and intention to quit waterpipe smoking in Lebanon: a cross-sectional study. Environ Sci Pollut Res, 26, 36647-57.

Heydari G, Zaatari G, Al-Lawati JA, et al (2018). MPOWER, needs and challenges: trends in the implementation of the WHO FCTC in the Eastern Mediterranean Region. East Mediterr Heal J, 24, 63-71.

Jaam M, Al-Marridi W, Fares H, et al (2016). Perception and intentions to quit among waterpipe smokers in Qatar: a crosssectional survey. Public Heal Action, 6, 38-43.

Jawad M, Charide R, Waziry R, et al (2018). The prevalence and trends of waterpipe tobacco smoking: A systematic review. PLoS One, 13, e0192191.

Jawad M, Jawad S, Waziry RK, et al (2016). Interventions for waterpipe tobacco smoking prevention and cessation: A systematic review. Sci Rep, 6, 1-8.

Jradi H (2017). Awareness, practices, and barriers regarding 
smoking cessation treatment among physicians in Saudi Arabia. J Addict Dis, 36, 53-9.

King JL, Reboussin BA, Cornacchione Ross J, Sutfin EL (2019). Waterpipe tobacco package warning exposure's impact on risk perceptions and use among young adults in the USA: a longitudinal analysis of the population assessment of tobacco and health study. Tob Control, 28, 16-23.

Martinasek MP, McDermott RJ, Martini L (2011). Waterpipe (Hookah) tobacco smoking among youth. Curr Probl Pediatr Adolesc Health Care, 41, 34-57.

Maziak W (2004). Tobacco smoking using a waterpipe: a re-emerging strain in a global epidemic. Tob Control, 13, 327-33.

Maziak W, Eissenberg T, Rastam S, et al (2004a). Beliefs and attitudes related to narghile (waterpipe) smoking among university students in Syria. Ann Epidemiol, 14, 646-654.

Maziak W, Ward KD, Afifi Soweid RA, Eissenberg T (2004b). Tobacco smoking using a waterpipe: a re-emerging strain in a global epidemic. Tob Control, 13, 327-33.

Maziak W, Ward KD, Eissenberg T (2004c). Factors related to frequency of narghile (waterpipe) use: The first insights on tobacco dependence in narghile users. Drug Alcohol Depend, 76, 101-6.

Primack BA, Sidani J, Agarwal AA, et al (2008). Prevalence of and associations with Waterpipe tobacco smoking among U.S. university students. Ann Behav Med, 36, 81-6.

Qasim H, Alarabi AB, Alzoubi KH, et al (2019). The effects of hookah/waterpipe smoking on general health and the cardiovascular system. Environ Health Prev Med, 24, 58.

Romani M, Jawhar S, Shalak M, Antoun J (2020). Waterpipe smoking cessation: knowledge, barriers, and practices of primary care physicians- a questionnaire-based crosssectional study. BMC Fam Pract, 21, 21.

Salloum RG, Abu-Rmeileh N, Hamadeh R, et al (2017). Policyrelevant context of Waterpipe tobacco smoking among university students in six countries across the Eastern Mediterranean Region: A Qualitative Study. Asian Pac J Cancer Prev, 18, 2533-2540.

Soule EK, Lipato T, Eissenberg T (2015). Waterpipe tobacco smoking: A new smoking epidemic among the young? Curr Pulmonol Rep, 4, 163-72.

Taylor D, Bury M, Campling N, et al (2006). A Review of the use of the Health Belief Model ( HBM), the Theory of Reasoned Action ( TRA), the Theory of Planned Behaviour (TPB ) and the Trans-Theoretical Model ( TTM ) to study and predict health related behaviour change. London, UK: National Institute for Health and Clinical Excellence, pp 1-215.

WHO (2019). WHO report on the global tobacco epidemic Summary of MPOWER measures in Saudi Arabia. https:// www.who.int/tobacco/surveillance/policy/country_profile/ sau.pdf.

WHO EMRO (2010). Tobacco Free initiative - MPOWER measures. In: World Heal Organ. http://www.emro.who.int/ tfi/mpower/index.html. Accessed 30 Dec 2020.

WHO Study Group on Tobacco Product Regulation (2015). Advisory note: waterpipe tobacco smoking: health effects, research needs and recommended actions by regulators, $2^{\text {nd }}$ edn. World Health Organization, Geneva.

\section{(ब) $(\otimes$}

This work is licensed under a Creative Commons AttributionNon Commercial 4.0 International License. 